\title{
Economía de guerra, frontera norte y formación de capitales a mediados del siglo XIX
}

\author{
Mario Cerutti \\ Universidad Autónoma de Nuevo León
}

\section{Resumen}

Nos interesa tratar aquí la relación que existió en estos tiempos tumultuosos entre las necesidades militares, los recursos y medios que se requirieron para solventarlos, y el rol desempeñado por fuertes comerciantes del noreste, muy particularmente los asentados en Monterrey. En este ensayo de corte histórico, que abarca los años de 1854 a 1867, se demuestra la forma en que el noreste de México jugó un papel importante, tanto para la defensa de sus estados fronterizos, como en el desarrollo económico de esta región, a través de un reordenamiento del poder regional que la época exigía.

Palabras clave: México independiente, arancel Vidaurri, economía de guerra, formación de capitales, reordenamiento de poder.

\begin{abstract}
Our interest in this research is the relation that existed during these troubled times between the military needs, the resources and means required to meet them, and the role performed by prominent businessmen from the Northeast of Mexico, particularly those from Monterrey. This historical essay, which includes the years from 1854 to 1867, shows how the Northeast of Mexico played a key role, both to preserve the border states, as for the economical development of this region, through the reorganization of the regional power that those times demanded.
\end{abstract}

Keywords: independent Mexico, Vidaurri customs fee, war economics, capitals formation, reorganization of power. 


\title{
ECONOMIA DE GUERRA, FRONTERA NORTE Y FORMACION DE CAPITALES A MEDIADOS DEL SIGLO XIX *
}

\author{
Por: Mario Cerutti **
}

\section{INTRODUCCION}

Los años que corrieron entre 1854 y 1867 resultaron decisivos en el devenir del México independiente: desde que se conoció el plan de Ayutla hasta la derrota de los invasores franceses se transitó un momen to clave para la configuración del estado nacional. Fue una coyuntura en la que era imposible predecir las características que asumiría dicho estado nacional, tanto territorialmente como en cuanto a la sociedad que le daría sustento. No era fácil asegurar, inclusive, que México proseguiría existiendo como país autónomo.

De manera análoga a lo que acaecía en otras regiones del continente, México se encontraba envuelto en intensas, implacables luchas civiles. Liberales y conservadores aparecían como los polos más visibles de un enfrentamiento que, finalmente, condujo a la intervención extranjera. La contienda ofreció aristas poco frecuentes en Latinoamérica por dos circunstancias; por un lado, debido a la solidez que presentaban los sectores conservadores, clara herencia de la estructura socioeconómica surgida en el período colonial, con la iglesia y el ejército como bastiones del viejo orden; por otra parte, cuando estalló la guerra de Reforma se estaba saliendo de uno de los mayores desastres que soportó México en el siglo XIX: la pérdida, frente a Estados Unidos, de una enorme porción del territorio heredado tras el agotamien to del imperio español.

Desde Ayutla y la posterior huida del presidente Antonio López de Santa Anna hasta la salida de las tropas francesas, las luchas interiores llegaron a su punto máximo. No puede extrañar, en este contexto, que semejante crisis política se manifestara abiertamente en el plano militar. La guerra sacudió el país a lo largo y a lo ancho, y una ingente gama de recursos fue volcada -por ambos bandos-en el sostenimiento de los ejércitos.

Hemos podido estudiar con cierta minuciosidad la mayor parte de este árido período en un área determinada de México: el noreste fronterizo. El espacio geográfico ocupado principalmente por los estados de Tamaulipas, Nuevo León y Coahuila -que con su actividad repercutía en un ámbito mucho más dilatado - se integró con vigor en los combates militares, y se tornaría en bloque un bastión para la causa liberal. Situados inmediatamente

\footnotetext{
* Investigador y docente en la Facultad de Filosofía y Letras, Universidad Autónoma de Nuevo León.

* Trabajo presentado en el Encuentro sobre la formación del capitalismo en México. El enfoque regional; ciudad de México, 24 y 26 de noviembre de 1983.
} 
debajo de la línea fronteriza que demarca el río Bravo, esos estados fueron capaces de armar gruesos contingentes bélicos y jugar un papel por momentos fundamental en la guerra civil.

Protagonista básico de lo ocurrido en el Noreste fue Santiago Vidaurri, quien desde 1855 -cuando se puso al mando de un ejército que llegó a tener más de cinco mil hombres - no sólo ocupó la jefatura de gobierno de Nuevo León (y de Coahuila, anexado en 1856 al anterior), sino que estableció un sistema de poder de características regionales que alcanzó notorio peso a nivel nacional. En 1864 fue destituido por el presidente Benito Juárez como consecuencia de su insistencia en sostener una política de autonomía con respecto al gobierno central, aún cuando fuese liberal; Vidaurri estableció (con algunos altibajos no significativos) su hegemonía en el Noreste: a la vez hizo de Monterrey, la capital de Nuevo León, el pivote político, militar y económico del área.

En una época en que resultaba arduo y casi impracticable, constituir un sólido poder central, el funcionamiento de lo que terminaría siendo el estado nacional mexicano dependía - como en otras latitudes de Latinoaméricade las fuerzas de carácter regional. Y dado que eran tiempos entrecruzados por constantes combates, un jefe regional en términos políticos debía ser también -como lo fue Santiago Vidaurri- un respetado comandante militar.

\section{EL NORESTE FRONTER IZO: LOS RECURSOS PARA LA GUERRA}

Nos interesa tratar aquí, brevemente, la relación que existió en estos tiempos tumultuosos entre las necesidades militares, los recursos y medios que se requirieron para solventarlas y el rol desempeñado por fuertes comerciantes del Noreste, muy particularmente los asentados en Monterrey.

Es pertinente acotar que tales necesidades eran acuciantes en esta amplia franja del territorio mexicano -además- por dos situaciones exclusivas del Norte. En primer lugar, por los permanentes problemas ocasionados por los ataques que contra las poblaciones del área lanzaban núcleos indígenas seminómadas, los que recorrían sin cesar un ancho espacio del sur de Estados Unidos y la parte septentrional mexicana. Con el cambio de la línea fronteriza, en 1848, y la rápida ocupación de Tejas, se intensificaron las incursiones de "los bárbaros". Santiago Vidaurri, precisamente, sistematizó el combate a muerte contra estos grupos que se habían negado a integrarse en la sociedad formada durante la colonia y que, a la vez, solían ser atacados sin piedad en Estados Unidos. En segundo término, Vidaurri debió mantener fuerzas prestas para repeler avances que sobre territorio de México efectuaban 
bandas tejanas (como el realizado contra Piedras Negras, en octubre de 1855): se temía que tras esos filibusteros se repitieran invasiones de la expansiva nación ubicada al norte del Bravo. ${ }^{1}$

A partir de la instauración de un poder de envergadura regional, según correspondía a una época de transición hacia la constitución del estado nacional, Santiago Vidaurri implementó un efectivo reordenamiento en el noreste fronterizo. Era un sistema que le permitía captar, con cierta rapidez, los recursos para solventar semejante aparato bélico. Su funcionamiento lo hemos descrito con mayor minuciosidad en otro trabajo ${ }^{2}$. Ahora sólo esbozaremos lo siguiente:

Paulatinamente, este gobernador fue adquiriendo una vasta experiencia en la tarea de montar, vestir, alimentar y armar ejércitos, a lo que seguramente contribuyó su exhaustivo conocimiento de las posibilidades de la frontera y su ya prolongada carrera en la administración estatal3. Cuando llegaron los graves tiempos de la Reforma - punto crucial en el camino de la revolución liberal-Vidaurri no sólo había transitado la labor de encabezar la insurgencia contra Santa Anna; enfrentó luego otras circunstancias críticas: los aprestos efectuados para responder a la invasión tejana, en octubre de 1855; el constante hostigar y repeler a los núcleos de indios que asolaban anchas franjas del norte mexicano; la crisis provocada por el levantamiento conservador de Puebla, en enero de 1856; e inclusive el choque contra otras fuerzas liberales que respondían al presidente Ignacio Comonfort, ocurrido desde septiembre de 1856 como consecuencia de la unificación de Nuevo León y Coahuila.

Esta actividad militar, con sus oscilaciones, provocó una densa demanda de recursos. Su cuantificación, con alguna aproximación, ha sido factible gracias a la muy minuciosa documentación que dejó en archivos la administración vidaurrista, especialmente por medio de su tesorería general. Esos papeles permiten, por ejemplo, señalar que desde el momento en que Vidaurri asumió el control de Monterrey y hasta fines de 1855, los gastos militares consumieron alrededor del 85 por ciento de los ingresos que contabilizó aquella oficina. Otros documentos muestran que entre noviembre de 1855

\footnotetext{
'La marcada autonomía que Santiago Vidauri sostuvo respecto a los mismos gobiernos centrales liberales le obligaba también a mantener tropas que, eventualmente, debian rechazar algún intento de sometimiento en el seno de esta corriente. Es lo que sucedió por ejemplo en 1856, cuando el presidente Ignacio Comonfort, dis gustado por la anexión que el gobernador de Nuevo León hizo de Coahila en febrero de ese año, lo enfrentó en términos militares. Esto explica, además, por qué el jefe fronterizo se negaba sistemáticamente a que tropas fe derales fueran enviadas al Norte, y a poner las suy as bajo órdenes de los comandantes generales que operaban en el centro de México

2 Véase Mario Cerutti, Liconomía de guerra y poder regional en el siglo XIX. Gastos militares, aduanas y comerciantes en wios de Vidaurri 18551864). Monterrey. Archivo General del Estado de Nuevo León, 1983.

3) Decumentación encontrada en el Archivo (ieneral del estado de Nuevo León (AGENL) indica que Vidaurri era ya empleado administrativo en el gobierno estatal hacia 1830. Escaló distintas posiciones hasta llegar a ser secretario general durante varios años y con diferentes gobernadores. Ejercía aquel cargo cuando se lanzó a la rebelión contra Santa Anna. en mayo de 1855 .
} 
y diciembre de 1856 dichos gastos absorbieron cerca del $80 \%$ de los recursos, mientras que si se alude al lapso que va desde mayo de 1855 , cuando Vidaurri se hace cargo del gobierno estatal, hasta septiembre de 1859 , cuando lo pierde circunstancialmente, la cifra vuelve a rondar el $850 / 04$.

Ya fuere para pagar los abastecimientos que la misma economía regional producía pese a su marcado carácter precapitalista 〈alimentos, animales para trasladar soldados y carga pesada, y una amplia gama de artículos artesanales como monturas, frenos, costales, mochilas, bolsas, entre muchos otros), como para cubrir lo que implicaba la importación de gran parte del vestuario y la totalidad de los pertrechos militares (armas, municiones, pólvora en cantidades considerables), Vidaurri acudió a dos fuentes principales de recursos: 1) las rentas que técnicamente debían corresponder al gobierno federal, entre las que sobresalieron con nitidez los ingresos aduanales y los impuestos a la circulación y/o exportación de metálico y, 2) los créditos y préstamos en efectivo de la más diversa índole que le facilitaban - amable o forzosamentelos mercaderes del área, entre ellos algunos situados en el sur de Estados Unidos y otros, los más asentados, en Monterrey. Ambas vías de acceso al financiamiento de guerra, por otro lado, se ligaban entre sí muy estrechamente.

En tanto entendía que sus ejércitos bregaban en defensa del orden liberal y por una causa nacional, Vidaurri absorbió sin prejuicios todas las rentas federales que se generaban en su ámbito de dominio. Lo efectuaba por momentos con la aprobación formal del poder central; pero en otras ocasiones llevaba a cabo esta política pese a las protestas ardientes de los gobiernos que intentaban imponer sus criterios desde el centro del país. Los tres presidentes liberales del período - Juan Alvarez, Ignacio Comonfort, Benito Juárez, debieron aceptar o resignarse a este manejo autónomo de los ingresos federales.

Dos de las medidas más espectaculares de Vidaurri, y que más controversias causaron en otras latitudes, fueron la habilitación de una línea de puestos aduanales sobre el río Bravo y la instauración de un arancel especial para las mercancías extranjeras, el que se haría famoso bajo el nombre de arancel Vidaurri. Un mes después de poner a Coahuila bajo su dominio militar y político (luego de la toma de Saltillo en julio de 1855), se comenzó a implementar este conjunto de decisiones. Entre agosto y octubre de 1855 -respondiendo en buen a medida a solicitudes de las poblaciones locales, pero también con el explícito consentimiento de los comerciantes de la región-el gobernador neoleonés disenó un funcionamiento aduanal arancelario que facilitaría no sólo la rápida obtención de recursos sino que permitiría a los traficantes ampliar sus mercados de manera generosa. El arancel Vidaurri, que se basaba en el fugaz antecedente fijado por el presidente Ceballos en enero de 1853 (cuando se intentó establecer un régimen sensiblemente liberal en la mate-

4Cerutti. op. rit. Las cilculos se fectuaron sobre la base de los cortes de caja y papeles complementarios

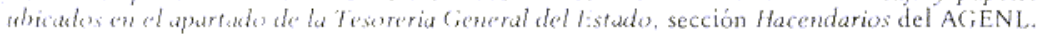


ria), fue readecuándose sucesivamente hasta significar, en los hechos, que las importaciones por la frontera noreste entraban con rebajas que redondeaban alrededor de un sesenta por ciento respecto a lo que soportaban artículos similares en otros puertos del país ${ }^{5}$.

En este contexto, el gobernador disponía de mecanismos eficaces no sólo para localizar recursos derivados de los impuestos que se cobraban, sino para llegar a rápidos acuerdos con los grandes comerciantes. Una práctica reiterada sobre todo en los momentos iniciales del período (hasta que se sistematizó justamente el funcionamiento del arancel Vidaurri), fue la de rubricar contratos especiales, particularmente para los abastecimientos de pertrechos bélicos. Según las urgencias financieras que generaba la guerra, el gobernador otorgaba rebajas más o menos marcadas a determinados intermediarios, en compensación por lo que se entregaba a sus ejércitos. Una segunda forma, que paulatinamente iría reemplazando a la anterior, fue la de solicitar préstamos destinados a cubrir los gastos militares: se devolvían con certificados que -presentados en los puestos aduanales- permitían efectuar importaciones masivas en el marco del ultraliberal arancel Vidaurri. Estos préstamos, además, recibían otra compensación: los fuertes intereses (premios) que le sumaban los mercaderes transformados en financistas del poder regional. En horas de extrema gravedad, como las que se vivieron justamente durante la guerra de Reforma, o como las que siguieron a la intervención francesa, esos premios llegaron a representar el cincuenta por ciento del dinero adelantado.

En cuanto al metálico -tanto amonedado como bajo otras características- consistía en un elemento estratégico para mantener relaciones fluidas con el mercado internacional y con los espacios más monetizados de la economía mexicana. La protección y control de su circulación fue otro instrumento que Vidaurri utilizó con el doble objetivo de localizar los siempre urgentes recursos que requería y de sostener relaciones amables (no exentas de presiones en ciertos casos) con los mercaderes. Extendido su poder político-militar a Coahuila, y vigilando los pasos principales que conducían hacia el puerto marítimo de Matamoros (el más usado por los traficantes del norte del país) obligó a que los impuestos a la circulación y exportación del

\footnotetext{
5 La habilitación de aduanas sobre la línea del Bravo fue resultado de medidas dictadas el 24 de agosto (Mier, Camargo, Laredo, Piedras Negras) y el 4 de octubre (Reynosa, Ciudad Guerrero). El arancel Vidaurri se implementó a partir del 22 de agosto de 1855, por una reforma que este gobernador ordenó al reglamento de aduanas marítimas y fronterizas que el lo. de junio de 1853 habia fijado el presidente Santa Anna. Vidauri hizo alterar los artículos 18,19 y 20 , y rebajó derechos de importación tomando como referencia el arancel Ceballos. Sobre tal base, el jefe neoleonés - de acuerdo con dirigentes tamaulipecos- comenzó a practicar des. cuentos que de un quince por ciento llegaron a alcanzar un cuarenta por ciento en 1857. Como esta sensible disminución repercutía sobre otros impuestos de manera proporcional (el de consumo, los municipales), la rebaja real se acercaba a un cincuenta por ciento de lo que establecía la ordenanza que en enero de 1856 sancionó Comonfort. Inclusive se han detectado alusiones a que la disminución era todavía mayor. Frente a las quejas que arribaban desde el centro del país, Vidaurri manifestaba que sólo cumplía fielmente lo que dictaba el articulo 70 del Plan de Ayurla reformado en Acapulco, que proponía un arancel en las aduanas marítimas y fronterizas tan liberal como el de Ceballos. La articulación progresiva del arancel Vidaurri, su repercusión (asi como las fuentes revisadas), ha sido tratado con mayor minuciosidad en Economía de guerra..., citado.
} 
metálico se pagaran en Monterrey. Por un lado, quien no respetase estas reglamentaciones sería acusado de contrabando, y su envío incautado; por otro, los que accedieran a abonar los recargos pertinentes en la capital de Nuevo León se beneficiaban con rebajas sensibles respecto a lo que se cobraba en otros puntos de salida, además de gozar de los múltiples beneficios del arancel Vidaurri. La administración vidaurrista no sólo se apropió de estos recursos, sino que llegó a autorizar sistemáticamente desde 1858 la exportación de plata pasta, prohibida de manera expresa por el gobierno federal.

Si bien este trabajo apunta a analizar el lapso global en que gobernó Vidaurri (1855-1864), por razones de espacio limitaremos nuestra descripción a dos aspectos: 1) el funcionamiento mercantil que posibilitó los contratos que efectuaba este jefe norteño en tanto iba definiendo su propio arancel, en un momento que comprende de mediados de 1855 a los inicios de 1857 ; 2) la forma en que encaró la grave situación generada a partir de 1858 , cuando estalla la guerra de Reforma. El estudio somero de estos dos puntos nos servirá para lograr una visión aproximada de los problemas que generó en el Noreste el mantenimiento de ejércitos, de los medios que se emplearon para ese fin y del papel jugado en tan críticos años por grandes comerciantes: agentes sociales, éstos, que en ese particular contexto lograban ampliar sus fortunas y transitar un escalón efectivo en el proceso de formación de capitales previo a la instauración de la producción capitalista en la región 6 .

\section{NECESIDADES MILITARES Y CONTRATOS}

Si bien el llamado arancel Vidaurri comenzó a delinearse con disposiciones adoptadas desde agosto de 1855, su cristalización demandaría tiempo. La experiencia contribuiría a configurar este arancel que llegó a implicar rebajas globales de considerable magnitud.

En tanto se afinaba este mecanismo - que sería un elemento clave en el sistema regional que funcionó en torno a Monterrey-, el gobernador Santiago Vidaurri utilizó en ciertos lapsos de extrema gravedad otra fórmula para lograr recursos de manera urgente: los contratos.

Fue un nudo fundamental en la relación que el poder político militar estableció con los comerciantes: cuando las necesidades y carencias arreciaban, los convenios facilitaban el abastecimiento de armas, de pertrechos de guerra,

\footnotetext{
5 fn nuestros estudios sobre la formación del capitalismo en Monterrey y en el noreste de México distinguimos dos subperiodos en la etapa que fue desde 1850 a 1910 . Entre la fecha inicial y 1890 se verificó un procesu de acumulación previa de capitales, sin una inserción cuantitativamente significativa en la producción capitalista. Haci. 1890 y hasta el estallido de la Revolución, una parte sensible de las grandes fortunas concen tradas en Monterrey se tranfirieron al sector productivo: los mecanismos capitalistas de producción se torna. ron relevantes. entunces, en Munterrey y en su ámbito regional. En el subperiodo 1850-1890, los años de San(iagu) Vidaturi emergen como lo más tempranos de esta fase de configuración de fortunas. Al respecto también preden consultarse M. Cerutti, Burguesial y' cupitalisho en Monterrey (1850-1910), México, Claves Latinoamericanas. 1983: Fromtera, burquesid repional y desarrollo capitalista. Ll caso Monterrey, en Roque Gonyález Salazar comp. La fromtera del nerte. Integracion y desarrollo, México, El Colegio de México, 1981
} 
de víveres, de vestimenta o de medios de transporte para hombres y carga pesada; también, de recursos en efectivo para las siempre maltrechas y ávidas finanzas del estado.

Los acuerdos de este jefe militar, que no eran exclusivos con los traficantes de Monterrey sino que se efectuaban con frecuencia con sus colegas de más allá del Bravo, provocaban revuelo y disgusto en el centro del país, e inclusive en el mismo Tampico, puerto que, por las interminables discordias que había en Tamaulipas, quedaba a veces al margen de esos mecanismos. Es que estos tratados se veían coronados por masivas y prolongadas importaciones que disfrutaban de rebajas generosas.

Fue sobre todo en las primeras épocas -el levantamiento contra Santa Anna y el sostenimiento del orden posterior, los aprestos contra tejanos y la guerra contra los indios, los preparativos ante el levantamiento de Puebla, la crisis que sucedió con el mismo Comonfort-cuando más abiertamente se instrumentó dicho método. Pero dado que sus repercusiones se dilataban durante meses, buena parte de las referencias quedaron asentadas en documentos de 1857, año en el que, por otro lado, el arancel Vidaurri llegaría a asumir su definitiva entidad.

Según el gobernador Vidaurri, debió recurrir al uso de contratos urgido por los acontecimientos pese a que, en un momento inicial; se oponía frontalmente a este tipo de relaciones con los intermediarios del área de frontera. Así le explicaba al ministro Manuel Payno, en abril de 1856:

\begin{abstract}
"Desde el 23 de mayo último que tomé la plaza de Monterrey, comenzaron los comerciantes a proponerme algunos negocios, ofreciéndome cuantiosas sumas de dinero para que les permitiera hacer sus importaciones de efectos en los términos y con las ruinosas condiciones que me proponían. Yo que siempre he visto con horror el que se despilfarraran los intereses nacionales con la quiebra de su valor efectivo tan sólo por satisfacer las ecsijencias del momento, ó por el aprovechamiento particular de los individuos que entraban en aquella clase de negocios, desprecié como era muy natural sus ofertas que por otra parte ofendían la dignidad del gobierno y ultrajaban la moral y la justicia en que este debe apoyar siempre todos sus actos."
\end{abstract}

Pasaron los meses de mayo, junio y julio de 1855 "luchando con toda clase de dificultades", hasta que debió habilitar -en agosto- las aduanas sobre el río Bravo y expedir medidas en materia de aranceles. En esos días, narraba Vidaurri a Payno, el mandatario de Tamaulipas, Juan José de la Garza, le insistía en la necesidad de entablar acuerdos (es decir, concretar contra- 
tos) con comerciantes de Monterrey y de otros puntos de la zona de frontera. Sus dudas y titubeos al respecto desaparecieron cuando se registró la invasión tejana, en el norte de Coahuila:

"Cuando me encontraba yo en aquellas apremiantes circunstancias apareció la invasión de los filibusteros tejanos en la frontera de Coahuila, y para rechazarla como lo exijían el honor y la dignidad de la Nación, me fue preciso mover con prontitud las tropas que tenía en esta Capital; pero no tenía un peso para socorrerlas. . y en este supremo evento me fue indispensable entrar en arreglos con varios comerciantes que me facilitaron el dinero necesario con algun descuento"7.

En posteriores comunicaciones a Payno, el jefe neoleonés le ampliaría sobre estos convenios y procuraría apaciguarlo ante las presiones que sobre el ministro acentuaban los alarmados comerciantes del centro del país. En mayo insistió en que, al principio, no quería meterse en este tipo de convenios, asegurando que mientras le fue posible acudió "a medios decentes para proporcionarme recursos" y que jamás consintió "los negocios que se me proponían por mas alagüeños que parecieran á primera vista"8.

Pero poco a poco su visión se modificaría: comenzó autorizando a Juan José de la Garza (que entonces era su segundo en el ejército del Norte), quien practicó acuerdos con comerciantes del sureste de Tejas y con otros con asiento en Matamoros. Cuando Juan José de la Garza dejó de obedecerle y se apropió de gran parte de los recursos que brindaban las aduanas del $\mathrm{Bravo}^{9}$, no le quedaron muchas alternativas:

"Sin fondos seguros para cubrir mensualmente los presupuestos de las tropas que han estado en constante y activo servicio, sin podérmelos proporcionar tampoco el Supremo Gobierno en virtud de las comprometidas circunstancias que lo han rodeado. . . sin esperan-

\footnotetext{
7 A(iENL. Correqundencia purticular de Santiage l'idaurri (CPSV), a Manuel Payno, 9 de abril de 1856.

${ }^{8}$ AciENL. (A)respondencia con el ministerio de Hacienda (CMH), 1856, 3 de mayo, Vidaurri señalaba: "desde que estayó la revolución en este Estado se me hicieron grandes ofrecimientos por el comercio con relación á recursos pecuniarios, por supuesto con la nira de obtener todas aquellas ventajas que en semejantes apremiantes circunstancias se procura con muy grave perjuicio de los intereses publicos; pero yo me había propuesto no abrir la puerta í tales escandalos rechacé la oferta al comercio y ocurrí al patriotismo de los Nuevoleoneses que the proporcionaron los recursos bastantes para organizar un ejército compuesto de muy cerca de tres mil hombres ale todas las armas. con el cual marché el 22 de junio ultimo sobre el (iral. Woll".

9 Juan Jusé de la (iarza, desde Tamaulipas. se negó a aceptar la hegemonía de Vidaurri en el Noreste. Frecuente a iado de los gobiernos liberales del centro, participó con sus tropas en los combates que enfrentaron al presidente Comonfort con el mandatario de Nuevo Leon-Coahuila en 1856. Esta actitud de De la Garza impidió muchits veces que Vidaurri pudiese controlar directamente las aduanas tamaulipecas, entre las que se contaban las dos marítinas: Matamoros y Tampico. La habilitación y posterior protección de una oficina en Piedras Negras habría sido un intento vidaurrista para contar con una aduana segura. Piedras Negras vivió momentos de notoria prosperidad desde mediados de 1861. cuando detonó la guerra civil en Estados Unidos y el algexdón de los plantiatores surenos salía hacia Europa por el noreste mexicano.
} 
za alguna de que pudieran venir por otro conducto que no fuera el de las aduanas del Bravo, cuyos rendimientos se hicieron ilusorios desde que metió la mano en ellas el Sr. Garza, no me quedaba otro medio que el de los contratos, ó el de retirar á sus casas á los soldados. .."

Tras luchar cinco meses con múltiples inconvenientes, resolvió ceder y plasmar estos convenios aún cuando reconocía que podían resultar "ruinosos a la hacienda pública y la naciente industria del país"10.

En otra misiva del 3 de mayo, Vidaurri anexó una relación sobre algunos convenios efectuados en 1855 y 1856. Uno de los casos citados se vinculó, según los comentarios que practica, a la promesa de enviar entre cuatro y cinco mil hombres para sostener a Comonfort "cuando asomó la reacción de Puebla", en enero de este último año. Como carecía de recursos, recurrió a tres grandes comerciantes de Monterrey (Valentín Rivero, Juan Clausen y Viuda de Tárnava y Cía., a los que se sumó Manuel María de Llano, de menor significación):

“. . se obligaron los contratistas á entregarnos dos mil rifles de Misisipi, quinientas carabinas de. . cañón grueso, dos mil quinientos polvorines y quinientas mil cápsulas, cuyos articulos habian de pagarse á descuento de derechos conforme el Arancel Cevallos. . . con deducción en todo de un cuarenta y cinco por ciento. .." 11.

También de 1856 fueron cinco acuerdos que resumió en un informe de octubre de 1859 el tesorero Domingo B. de Llano y que se habían efectuado con Patricio Milmo (20 de septiembre), Clausen y Compañía, Juan P. Molony, Santiago Grogan y José Moses (12 de octubre estos últimos). Las deudas contraídas se cubrirían con derechos sobre importaciones a realizar por las aduanas fronterizas de Camargo y Mier, bajo el a ancel Vidaurri y un descuento global del 35 porciento. Fueron, éstos, los días en que Vidaurri se armaba para combatir al propio Comonfort. El jefe neoleonés ocupó lo más rápidamente que pudo dichas aduanas, y las utilizó para localizar recursos: la vinculación entre dominio de estos puntos de introducción de mercancías, necesidades militares y sentido de la oportunidad por parte de los traficantes, resulta evidente.

Cuando quedó sellada la paz entre Vidaurri y Comonfort, por medio del tratado de Cuesta de los Muertos, en noviembre de 1856, el gobernador neoleonés solicitaría a Vicente Rosas Landa, representante del presidente, que gestionara la aceptación de algunos de estos convenios. El 25 de noviem-

10A(;ENL. C.MH. derimentus citado.

11 AG:ENL. CMH, 1856. 3 de mayo. Los convenios con estos comerciantes se firmaron el 5 de marzo de 1856. 
bre escribía a los diputados Manuel Gómez y Miguel Blanco y señalaba que en aquellas deliberaciones con Rosas Landa había propuesto que el ejecutivo nacional ratificara los negocios que tuvo que efectuar

"con cinco casas de la banda izquierda del Bravo para proveerme de dinero, artículos de boca y guerra y vestuario para la tropa, descansando el valor de todo lo que aquellas me ministraron á la suma de doscientos cincuenta y nueve mil pesos."

Pedía a los legisladores que aceleraran este trámite y que solicitaran a Comonfort que autorizara

"el paso de mil fusiles, seiscientos rifles, con pistolas de repetición, cuatrocientas mil capsulas y seiscientas arrobas de polvora pertenecientes á los contratos anteriores por ser éstos de suma importancia para la frontera que constantemente se ve amagada por los indios bárbaros..."12.

A principios de 1857 , y pese a los antecedentes, Comonfort aprobó estos contratos.

Las referencias se reiteran en la documentación revisada. Comerciantes asentados en Monterrey (Clausen, Rivero, Milmo, Mariano Hernández) o que operaban en un contexto regional que incluía el sur de Tejas (Juan Molony, José Moses, Ernesto Dillon, Santiago Grogan, Antonio de la Garza y Chapa, entre otros) usufructuaron este tipo de vinculaciones con el poder político y militar. Situación que, además, se reproducía en Tamaulipas: tanto Juan José de la Garza como su segundo, el comandante de la línea del Bravo, Guadalupe García, rubricaban con mucha frecuencia convenios de esa naturalesa ${ }^{13}$.

\footnotetext{
12 AGENL, Minutas, 1856, 25 de noviembre. La referencia del tesorero De Llano está en Hacendarios, 1859. 24 de octubre. Los montos involucrados en esos convenios eran: Patricio Milmo, 42480 pesos; Juan P. Molony, 56 195.25; Clausen y Cía, 78 902.75; Santiago Grogan, 38 422; y José Moses, 43 000. No era cierto pues que los acuerdos se hubiesen hecho exclusivamente con "casas de la banda izquierda del Bravo", pues entre los citados estaban comerciantes de Monterrey.

13 Datos sobre uno de los contratos que formalizó Guadalupe García con Antonio de la Garza y Chapa - repre. sentante de la casa Viuda de Támava y Cía, que tenía locales en Monterrey y Matamoros- se encuentran en la correspondencia de ese militar con Vidaurri, 29 de enero de 1856. El mercader adelantó a García 20,000 pesos, a pagarse con derechos de importación. El 5 de marzo, el jefe de la línea del Bravo comunica al manda. tario de Nuevo León-Coahuila que, ante la necesidad de enviar con urgencia a Tampico cuatrocientos hombres. tuvo que practicar un contrato con Luis Blacker: importará por Reynosa efectos con derechos que pasan los 6600 pesos. El 30 de abril de 1856 indica a Vidaurri que ha celebrado convenio con Benjamín Burchard: proveerá armas a sus tropas y será compensado con derechos para importar. García dice que sólo le aplicó un 30 por ciento de recargo sobre el valor de las instroducciones, montó bajísimo que sólo en algunos momentos fue superado por Vidaurri (hay alusiones a un 25 por ciento). El arancel Vidaurri, pese a lo liberal que era, estaba por encima de tan escasos recargos. Las importaciones de Burchard se efectuaron por Camargo. El 12 de mayo García solicitó a Vidaurri que no interfiriera el tráfico que llegaría desde Reynosa: Fernando Manatou
} 
Durante 1857 pareció acentuarse el impacto de este movimiento mercantil que se desplazaba desde la frontera noreste, y que combinaba las aún vigentes repercusiones de los contratos con la decidida articulación y funcionamien to del muy liberal arancel Vidaurri. En mayo encontramos alusiones al convenio efectuado en marzo de 1856 con Valentín Rivero: la tesorería del estado debía liquidar derechos sobre efectos "ultimamente importados. . . hasta cubrirle el crédito que tiene". En agosto continuaba en acción el acuerdo plasmado con Molony el 1o. de noviembre de 1855: introducciones que practicaba por Mier compensaban un préstamo "que hizo en S. Luis Potosí el Ejército del Norte"14.

No puede extrañar que desde la Secretaría de Hacienda se enviara el 2 de noviembre un oficio en el que se amenazaba con drásticas medidas si no cabrían los requisitos que se indicaban.

"Siendo ya notables las introducciones de efectos que procedentes de la frontera se han hecho en algunas poblaciones del interior y aun en esta misma capital, y presumiéndose que por el bajo precio á que se venden en la plaza a pesar de los mayores costos de flete y riesgos del camino, que han sido introducidas de contrabando, ó por lo menos no han pagado los derechos de importación que señala ordenanza vigente de aduanas marítimas (el presidente resuelve que) ninguno de los cargamentos que vengan de la frontera se reciban en aduanas interiores de los Estados y Capital de la República. . ."

De lo contrario, caerían "irremisiblemente en la pena de comiso....". Se recomendaba expresamente al gobernador que contribuyera a contener "el abuso que se hace por esa frontera" en la introducción de efectos "sin el pago de derechos y sin las formalidades necesarias"15.

Alarmado, Vidaurri escribió al diputado Blanco el 1o. de diciembre, adjuntándole documentación que aludía a demandas elevadas por Juan Clausen y Patricio Milmo ${ }^{16}$ para que se revocara la disposición federal. Y recordaba:

\footnotetext{
y Garza y Chapa iban a remitir más de doscientos bultos con mercancías con sólo 30 por ciento "por todos derechos". Los casos abundan; los comerciantes solían usufructuar al máximo estas concesiones. Daniel Wolf, de ciudadanía estadounidense, que tuvo múltiples tratos con Vidaurri, llegó a asustar en cierta ocasión al propio García. El comandante de la línea del Bravo se quejó el 19 de marzo que Wolf, pese a que debía concretar una importación por Matamoros por alrededor de 4000 , pesos, según acuerdos previos con el mandatario de Nuevo León-Coahuila, estaba abusándose: "el caso es, que ahora ha importado cosa de ochenta mil, no siendo ésto lo peor, sino que Wolf ha convidado á una porcion de comerciantes á que introduzcan con él sus efectos". Vidaurri mostrará enfado ante esta noticia, al menos en apariencia, y prometerá sancionar a Wolf.

14 AGENL, Hacendarios, 1857, 2 de mayo y 25 de agosto.

15 AGENL, CMH, 1857-58, 2 de noviembre.

16 Patricio Milmo se convirtió en yerno de Santiago Vidaurri en 1857. Fue uno de los grandes usufructuarios de este sistema regional de poder. Su importancia será visible, asimismo, en el proceso de industrialización iniciado hacia 1890 .
} 
"Estos contratos se hicieron por mi para la guerra en la revolución contra Santa Anna, y se hicieron con el objeto de pagar los crecidos gastos de mas de cinco mil hombres que tuve que levantar, vistiendolos, montandolos, armandolos y pagandolos, ademas estableciendo una maestranza que constantemente trabajó; y esa cantidad que importaron los contratos es nada en comparación de lo que gastó en esa misma revolución el Estado, el que hizo un gasto de mas de un millon de pesos".

Recordaba que en enero de 1857 habían sido aprobados por el ejecutivo nacional. Empero,

" los interesados no han podido traer todos los efectos que debian por tales contratos, porque han tenido que limitarse á ir importando conforme han vendido; mas con la seguridad que les dio esa. . aprobación del gobierno mandaron traer mercancías á Londres, Francia y Alemania, y de esos efectos unos estan en camino y otros del otro lado del Bravo".

Refutaba de paso la apreciación ministerial:

"Se cree que los efectos importados por virtud de esos contratos han ido hasta México, considerandose al mismo tiempo, que por aquí se hace el contrabando; en esto hay una equivocación, al mismo tiempo que se me hace una injuria, por no creerseme; pues hasta el fastidio he repetido en lo particular y oficialmente por escrito y de palabra, que por aquí no se hace ni puede hacerse el contrabando..."

En su entender, era por Tamaulipas -es decir, por los puntos aduanales que Vidaurri no controlaba entonces, como Matamoros y Camargo- por donde ingresaban tantos artículos extranjeros. Lo que no aclaraba era que en Tamaulipas, simplemente, seguían su ejemplo, y que Monterrey se beneficiaba indirectamente con estas masivas importaciones por cuanto era el centro distribuidor principal de un ancho espacio regional: consecuencia de ser, a la vez; asiento del poder político y militar predominante en el Noreste, y de su adecuada posición geográfica.

Este conjunto de datos (y la competencia decidida que entre los jefes locales se desarrollaba por los recursos que brindaban aduanas y mercaderes) era sintetizado por el mismo Vidaurri:

“. . esas importaciones (las provenientes de Camargo y Matamoros, $\mathrm{MC})$, que se hacen por derechos insignificantes, son los efectos que han ido á México. Recojanse si no las guias espedidas por Camargo y Matamoros de dos años á esta parte y que se encuentran en las administraciones de rentas de esta ciudad, Matehuala, Catorce, San 
Luis, Zacatecas, Chihuahua, Durango y otros puntos de aqui del interior, liquidense y preguntese á los empleados de Matamoros y Camargo en que han invertido los derechos causados por esas importaciones, y se verá palpablemente lo que he dicho. Esas importaciones hechas por Matamoros y Camargo han impedido también á los contratistas acabar de hacer sus introducciones, porque no pueden competir con los otros comerciantes. .."17

En verdad, desde México se desconfiaba de las autoridades norteñas, y muy particularmente del siempre autárquico Vidaurri. Ya a mediados de abril de 1856 el ministro Payno le había recomendado explícitamente que remitiera información sobre "los bultos que se hayan introducido por contratos consumados y concluídos por V.E.", porque había constantes reclamaciones "y dificultades con el comercio" Payno se refería seguramente a los comerciantes del área central del país ${ }^{18}$.

Las presiones del poder federal se extendían a los funcionarios regionales adeptos al gobernador. El 11 de mayo de 1856, el administrador de la aduana de Laredo - muy amigo de Vidaurri- escribía a Ignacio Galindo, secretario de Guerra de Nuevo León-Coahuila:

"Ya me come el Ministerio, y por otro lado la Junta de Crédito Público pidiéndome informes de cuanto les viene á la cabeza. Ultimamente me preguntan cuales son los contratos que ha celebrado D. Santiago, en que cantidades, y cuales son sus términos; y debiendo contestar hoy no lo he hecho, por no estar instruido en los pormenores de los dos únicos que yo sé, cuales son el celebrado con D. Eduardo (Jordán) y el pendiente con la casa de Dwyer. Quisiera saber si nuestro amigo está por que se den tales informes, y en este caso cuento con las instrucciones de U. sobre el particular".19

Aunque desde Monterrey se negaba por distintos conductos 20 que el poder regional con base en esa ciudad tuviera qué ver con estos tráficos, que

17 AGENL, CPSV, a Miguel Blanco, 1 de diciembre de 1857. Según el gobernador, sus primeros contratos - hemos visto ya- los había efectuado cinco meses después de ocupar Monterrey. En esta misiva, en cambio, detalla sobre convenios realizados "para la guerra en la revolución contra Santa-Anna". La contradicción es evidente: los informes que el jefe norteño transmitía al gobierno central se sometían a la coyuntura que transitaba. La única manera de ratificar o rectificar el contenido de estas comunicaciones es escrut ar la enorme masa de papeles que existen en Monterrey. Como en otros casos, ello reafirma la necesidad ineludible de trabajar los archivos estatales. Sin esta búsqueda en provincias, el siglo XIX continuará siendo un período con demasiados momentos y procesos oscuros.

18 AGENL, CMH, 1857, 15 de abril. Vidaurri respondió que era imposible informar en detalle sobre las introducciones realizadas, aunque por separado remitió una noticia de los contratos celebrados.

19 AGENL, Ramo Militares, 1856, 11 de mayo. La casa de J. A. Dwyer (o Dwyen) funcionaba en Laredo Texas.

20 f:l Restaurador de la Libertad, órgano oficial del vidaurrismo, refutaba en octubre de 1857 apreciaciones que se hacían en una carta originada en Tampico, y reproducida por Le Trait d'linion el 17 de septiembre de ese año. "Cualquiera se figurará que no existen ya casas (en Monterrey) en donde encerrar cargamentos", respondía. El Restaurador, 2 de octubre de 1857. 
se intensificaron, al parecer, en 1857 la documentación que hemos revisado dice otra cosa. Obsérvese por ejemplo el anexo I. Se trata de una Noticia de las guías que acompañaban los cargamentos procedentes de los puertos fronterizos y marítimos del Noreste, y que se registraron en la Administración de Rentas del Estado entre el 25 de agosto y fines de septiembre de ese año: treinta y cinco días en los que entraron a Monterrey casi cuatro mil bultos con artículos importados.

Es interesante tener en cuenta los destinos declarados: además de Monterrey, Saltillo, Parras y comarcas aledañas, figuran la ciudad de México, Chihuahua, Zacatecas, San Luis Potosí, Durango, San Juan, Guanajuato y hasta Colima. La Noticia señala, simplemente, que sobre la base del arancel Vidaurri (que no sólo funcionaba en las aduanas bajo control del gobernador, sino que se había generalizado en las restantes) y de los contratos que se habían sellado en los dos años anteriores, los mercaderes de la región se enlazaban cómodamente con el mercado mundial y podían competir en lugares muy distintos del mercado nacional. pese a las malas comunicaciones de la época. Esto se veía forzado por descuentos complementarios que disfrutaban en la circulación y exportación del metálico, renglón que será sistematizado -como se verá- desde 1858. La ciudad de Monterrey, al amparo de un sistema regional de poder, militar y político, emergía como un centro estratégico para la redistribución de tal flujo de introducciones.

El propio Comonfort se mostraba preocupado, y soportaba fuertes reclamos de los comerciantes de Veracruz y México. El diputado Miguel Blanco le describía a Vidaurri, el 14 de octubre de 1857, ciertos aspectos de una entrevista que había mantenido con el jefe del ejecutivo nacional, en la que se trató este tema. El presidente aludió al contrabando y a las masivas importaciones que se practicaban el el Noreste, y le dijo el legislador que no encontraba otro medio para contrarrestar tal flujo que,

"no dejar mas de una aduana de las del Bravo (la de Matamoros) para el comercia de altura, reducir las demás á de cabotage y para la importación y exportación de víveres, y el restablecimiento del contra-resguardo."

Las quejas de los intermediarios del centro señalaban rotundamente que: la baratura inconcebible de los efectos que venían de las aduanas del Brabo no procedían de contrabando, sino de las rebajas de derechos que sus empleados, de su autoridad o con consentimiento del gobierno, hacían a los introductores. . ."21

Pero la crisis que derivaría en la guerra de los tres años estaba encima. Al caer Comonfort e instalarse a principios de 1858 un gobierno conservador en

21 AGENL, CPSV. de Miguel Blanco. 14 de octubre de 1857. 
el centro del país, la lejana frontera del Noreste acentuaría su autonomía y, a la vez, se lanzaría a la defensa del orden liberal.

\section{EL NORESTE EN LA GUERRA DE REFORMA}

De los tres años que duró, en líneas generales, la guerra de Reforma, trataremos en este apartado los meses que corrieron entre enero de 1858 y septiembre de 1859. Este último corte lo efectuamos porque, en ese mes, Santiago Vidaurri fue derrocado momentáneamente por grupos liberales locales ligados al comandante de las tropas reformistas, Santos Degollado 22 . La documentación revisada, correspondiente a estos veintiún meses, brinda datos suficientes para obtener una impresión relativamente firme en torno al tema que nos preocupa.

Podría comenzarse detallando que, conocido el plan de Tacubaya, los estados del Noreste recobraron su autonomía y se lanzaron a preparativos intensos en defensa del orden liberal. Nuevo León-Coahuila consideró que se habían vulnerado instituciones sustanciales: "El pacto fundamental de la República ha sido roto por una facción crminal y traidora", que consumó "un escandaloso motín". El país había quedado sin representación ni poderes legítimos. Mientras la república permaneciese acéfala, ese estado recobraba.

" la plenitud de sus derechos, reasumiendo su soberanía y quedando en libertad para dictar cuantas medidas juzgue necesarias para su conservación y defensa de las instituciones democráticas. "23

Actitudes análogas se habían manifestado en Tamaulipas. El gobernador Juan José de la Garza suscribía el 28 de diciembre un decreto en el que se mencionaba:

"Roto el pacto federal que actualmente une a los Estados de la República, el de Tamaulipas reasume su soberanía, desconoce al Gobierno del centro y seguirá rigiéndose por sus instituciones particulares hasta el restablecimiento de la constitución del 5 de febrero de 1857."

Además, y éste es un dato significativo para lo que diremos más adelante, el congreso tamaulipeco autorizaba al ejecutivo a "ocupar las rentas generales de la Federación existentes en el estado, incluso los productos de las

\footnotetext{
22 Vidaurri retiró sus ejércitos en medio de la guerra de Reforma porque se negó a aceptar cl mando de Degolla do, suceso que ratifica lo que se expresa en la nota 1 . Como respuesta, el general Degollado, con la aprobación de Benito Juárez, estimuló un movimiento contra el gobernador en Nuevo León y designó en su reemplazo a José Silvestre Aramberri. Al poco tiempo Vidauri recuperó el poder.
}

${ }^{23}$ AGENL, Boletin Oficial, 23 de enero de 1858. 
aduanas marítimas y fronterizas", y a "espedir aranceles y cobrar los derechos en ellos establecidos a los efectos de procedencia nacional o estrangera" 24

Si hasta esos momentos Vidaurri y de la Garza habían mantenido discrepancias profundas, aún cuando ambos eran liberales, el pronunciamiento de Tacubaya los uniría. En enero de 1858 rubricaron a un pacto, en Montemorelos, que consolidaba "una alianza ofensiva y defensiva para sostener la constitución de 1857". Se comprometían a levantar "el mayor número de fuerzas que les sea posible para el sostén de la causa nacional", y poner en marcha lo antes posible operaciones militares sobre Tampico y San Luis. 25

Desde los inicios de 1858 se multiplicaron en Monterrey los esfuerzos para conformar un poderoso contingente militar, repitiendo experiencias vividas en 1855, cuando se generó el levantamiento contra Antonio López de Santa Anna. El 24 de marzo, el Boletín Oficial - hoja vidaurrista- detallaba la salida de un cuerpo de infantería al mando de quien luego se convertiría en un célebre general, Ignacio Zaragoza:

"... consta de mas de seiscientas plazas y con la infanteria del Saltillo y Parras que se le ha de incorporar en aquella ciudad, asciende el número de infantes. . a poco más de mil. Este batallón va perfectamente bien armado, municionado y vestido. Todo lleva nuevo, armas, vestuarios, correage, etc. Treinta y cinco carros acompañarán á esta hermosa sección. En ellos se lleva una gran cantidad de parque, víveres y muchas armas para armar cuatrocientos infantes que deben salir del Valle de Purisima y algunas otras fuerzas de los pueblos que están del otro lado de la sierra. Seis piezas de artillería muy bien montados y con sus respectivas dotaciones, y el magnífico regimiento de caballería que conduce (el coronel) Miguel Blanco forman el complemento de esta respetable sección de guerreros fronterizos, a quienes muy en breve seguirá la que ha de conducir el mismo Sr. Vidaurri, compuesta de las tres armas, con las que se completarán cinco mil hombres solo del estado de Nuevo León y Coahuila."26

La actividad era ferviente. En abril, Vidaurri escribía a otro importante subordinado, Juan Zuazua, describiéndole:

"Dentro de seis días quedarán montados y enteramente útiles dos de nuestros obuses de á treinta y seis, y en diez ó doce días mas se con-

$24 \mathrm{Idem}, 5$ de enero de 1858.

25 AGENL, Minutas, 1858,13 de enero.

26 AGENL, Boletin Oficial, 24 de marzo de 1858. 
cluirán los otros dos; desde hoy se han dado por tarea diaria veinticinco mil cartuchos; ayer recibí doscientas arrobas de pólvora excelente; dentro de ocho días volverá Torralba de China con trescientos caballos para montar doscientos rifleros de Río-grande (...) en el mismo tiempo me vendrán de Linares doscientos caballos y ciento cincuenta mulas de sillas, y en quince o veinte días (tendremos aquí) seiscientos caballos. . "27

No extraña así que a medidados de mayo el Boletín Oficial reseñara, no sin cierto orgullo fronterizo:

"Lo que pasa en el Estado actualmente no se puede creer sino por lo que vemos. Más de cinco mil hombres andan en campaña, armados la mayor parte de ellos con armas nuevas enteramente y de la mejor clase que se conoce; ha habido necesidad de comprar caballos, sillas, etc., etc., y todo se ha estado pagando con exactitud ¿De dónde se ha sacado tan to dinero para hacer estos inmensos gastos? ¿Cómo ha podido el Sr. Vidaurri parar un ejército tan respetable y poderoso en un Estado tan pequeño y tan pobre, cuando en otros Estados grandes, ricos y florecientes no se ha podido hacer lo mismo?"28

Era sin duda, esta última, una pregunta pertinente.

\section{Mercaderes y prestamistas}

Al revisar el ya citado pacto de Montemorelos, de enero de 1858 , es factible suponer la dimensión que asumió la movilización militar impulsada desde el extremo noreste. En su artículo 5o. decía que para poder

" llevar á efecto las operaciones militares, se negociará un préstamo dentro ó fuera de la República hasta de quinientos mil pesos, hipotecando para su pago los productos de la Aduana marítima de Tampico y de las fronterizas del río Bravo (por lo que ambos estados se comprometen a) no celebrar mas contratos que los que tengan por objeto el adelanto de derechos por importaciones conformes al arancel ".

El arancel al cual se refería el convenio no era, por supuesto, el fijado por el gobierno liberal de Ignacio Comonfort en enero de 1856. Se trataba del arancel Vidaurri, que ahora sería incorporado de derecho (mientras que antes había funcionado de hecho) en la propia Tamaulipas: "Mientras duren las actuales circunstancias regirá el arancel conocido con el nombre de Vidaurri, que espedirá el señor Garza, con la baja de un cuarenta por ciento...."

${ }^{27}$ Idem, 22 de abril de 1858 .

28 Idem, 14 de mayo de 1858 . 
En el artículo 8o. se mencionaba el envío a los Estados Unidos de

" uno ó dos comisionados para agenciar el préstamio de que habla el artículo quinto, pudiendo recibir la mayor parte en numerario y el resto en armas y municiones de guerra, que por ahora serán cuatro mil rifles, ocho mil fusiles, mil pistolas de seis tiros y la pólvora que se considere necesaria.,"29

Nueve días más tarde, el 22 de enero, se emitía en Monterrey una circular destinada al comercio. luego de resumir la circunstancia política que había detonado con el levantamiento conservador, y reiterar el compromiso del estado de Nuevo León-Coahuila en una lucha que debía lograr "el restablecimiento neto de la Constitución de 1857, atacada de muerte por el motin militar de Tacubaya", se aludía a los aprestos bélicos que era menester desenvolver. Los gastos serían enormes, proporcionados a la empresa que debía acometerse. Entre los recursos con que se podía contar figuraba.

" el producto de las aduanas del Bravo, incluso el de la de Piedras Negras, que debe partirse por mitad entre Tamaulipas y Nuevo León y Coahuila para sus operaciones militares, según la alianza que acaban de celebrar ambos Estados (...) Se ve por lo dicho que los dos gefes al concertar sus medios ofensivos y defensivos han fundado sus esperanzas, entre otras cosas, en el comercio si él sabe corresponder á la protección que se le dipensa en el arreglo que han hecho respecto del ramo mercantil. . .'

Esto implicaba el funcionamiento del arancel Vidaurri, reducciones proporcionales de impuestos complementarios y rebajas para la circulación y exportación del metálico. Sumadas todas estas ventajas, "los derechos que pesaban sobre el comercio quedan reducidos á poco menos de la mitad de los que establece la ordenanza general de aduanas". Los comerciantes, pues, no podían "esperar mas proteccion que la que se le dispensa por este arreglo". Y ya que era así, en tanto comenzaban a recaudarse en las aduanas los productos ordinarios, y ante las urgencias que planteaba la movilización de las tropas, el gobierno de Nuevo León-Coahuila acudía a los mercaderes "solicitando un anticipo á cuenta de derechos de importacion y de consumo". Este patriótico servicio sería comprensado, además, con un premio del 11 por ciento: "esto es, por cada cien pesos (se) les pagará ciento once". Y cerraba:

"La Tesorería general del Estado estenderá á favor de los anticipantes un documento en que consten las cantidades anticipadas con el aumento del once por ciento, y este documento servirá á los intere-

29 AGENL, Minutas, 1858,13 de enero. 
sados para que paguen con él los derechos que causen las importaciones de sus efectos por cualquiera de las aduanas espresadas y también el de exportación y consumo." 30

Los meses que corrieron desde principios de 1858 hasta septiembre de 1859 se situaron, en términos generales, en este contexto. Un sistema regional que se delineaba sobre todo en torno a Monterrey, centro político-militar fundamental del Noreste, con bifurcaciones hacia algunos puntos claves en Tamaulipas: Tampico, en parte, y sobre todo Matamoros, cuya importancia residía en que eran asientos de aduanas marítimas significativas. Y la necesidad perentoria de efectuar grandes importanciones de armamentos y pertrechos, de recurrir complementariamente a la economía regional para otros abastecimientos esenciales. Como se indicó en un segundo convenio firmado entre de la Garza y Vidaurri -el de Ciudad Victoria, de mediados de diciembre de 1858- la dinámica militar se mantuvo con el máximo de vigor:

"Mil quinientos ó dos mil hombres de Tamaulipas de todas las armas, y toda la fuerza de Nuevo León y Coahuila en un numero de cuatro mil hombres, abriran la campaña por el rumbo de San Luis Potosí. En este punto se incorporaran los nacionales del mismo Estado, que apresten sus autoridades legitimas hasta el numero de tres mil hombres de infanteria y caballeria; los nacionales de Zacatecas en numero de dos mil, y los de Chihuahua y Durango en el de mil quinientos."

Tanto esfuerzo, generado por las "circunstancias angustiadas por que atraviesa el pais", se impulsaba en fuerte medida desde el Noreste empleando "toda clase de renta pública" 31 . Pero además obligaba a recurrir de manera constante a los grandes mercaderes, a quienes se compensaba préstamos y créditos tan riesgosos con rebajas drásticas en los derechos de importación, con premios oportunos sobre el dinero facilitado, con disminuciones en los impuestos a la circulación del metálico, con autorizaciones para exportar plata en pasta y con una protección general que los ponía en óptimas condiciones para que los artículos introducidos por esta área de la frontera compitieran en una parte amplia del territorio nacional.

Las finanzas de la guerra

Nos detendremos brevemente, ahora, en los anexos II y III, elaborados sobre la base de la documentación encontrada y revisada en archivos de Monterrey.

El primero de ellos incluye cifras de los cortes de caja de la Tesorería General del Estado, entre enero y septiembre de 1858. Figuran, mes a mes,

30 AGENL, Circulares, 1858, 22 de enero.

31 AGENL, Ramo Militares, 1858/1,19(?) de diciembre. 
los ingresos y egresos globales de esta oficina, además de mencionarse los diversos rubros que los integraban. Pese a que comprende sólo nueve de los veintiún meses que involucró la coyuntura que analizamos, muestra tendencias que pueden tenerse en cuenta, sobre todo si se recuerda que esta fracción de 1858 fue de enormes movimientos castrenses.

En el rubro ingresos, la tesorería contabilizó en este lapso 661,823 pe$\operatorname{sos}^{32}$. De ellos, como indica el anexo II, el 35.54 o/o fueron localizados por medio de los préstamos de pronto reintegro, solicitados generalmente como anticipos a los comerciantes. Un $3.75 \%$, a su vez, proviene de las remisiones aduanales ${ }^{33}$, que en su mayoría llegaban desde la marítima y fronteriza de Matamoros, en el extremo norte de Tamaulipas. Quiere decir que entre ambos rubros se alcanzó casi el cincuenta por ciento de los ingresos que computó la tesorería, aunque es bien claro que hay marcadas oscilaciones de mes a mes. Más atrás quedan, así, otros ítems: alcabalas (que era el principal entre los restantes), los contingentes que cubrían los pueblos del estado, la venta de terrenos baldíos, los recursos que comenzaron a surgir con la aplicación efectiva de las leyes de desamortización.

En cuanto a los egresos, los pagos efectuados en función a los préstamos de pronto reintegro absorbieron el $22.75 \%$, en tanto que el rubro gastos extraordinarios de guerra se llevó el 38.33 \% de lo gastado por tesorería. Deben practicarse aquí dos aclaraciones: a) una porción de lo devuelto por los citados préstamos se incluía en los gastos extraordinarios de guerra, por lo que su monto real es mayor al porcentaje apuntado; b) el rubro "extraordinario de guerra" fue creado por la administración vidaurrista para justificar la apropiación de recursos federales. En tanto los ejércitos norteños luchaban por una causa nacional, no quedaba otra alternativa que tomar esas rentas. Esas transferencias se computaban, a veces, como provenientes de la jefatura de Hacienda del Estado, una oficina que formalmente dependía del gobierno supremo, pero que siempre estuvo bajo el dominio de Vidaurri. En los cortes de caja de la tesorería sólo en algunas ocasiones se anotaban estas remisiones. 34

Entre los pagos por préstamos y los gastos extraordinarios de guerra se llegó en estos meses a casi el $60 \%$ o de los egresos de la tesorería, entre los que no figuran -como sí ocurría hasta fines de 1856- los llamados "gastos ordinarios de guerra". Estos últimos -en la óptica de la administración de

\footnotetext{
${ }^{32}$ Se han descartado del cálculo las existencias, que en los cortes de caja se contabilizaban como parte de los recursos disponibles. Se trataba de elementos y a veces de dinero sobrante de meses anteriores. Por lo que no pueden ser incorporados a las entradas netas que presentaba la tesorería.

33las remisiones de las aduanas figuran desde marzo. probablemente porque a partir de entonces comenzó a tener vigencia efectiva el pacto de Montemorelos (firmado a mediados de enero) en lo que hacía al reparto de esits rentas.

34 )ichas remisiones quedaron apuntadas, por cjemplo. en los meses de enero y febrero de 1858. Luego desaparecen.
} 
Nuevo León-Coahuila- correspondían al propio estado: eran distribuidos vía la Pagaduría General del Ejército del Norte, a cuya cuenta no hemos tenido acceso. ${ }^{35}$

Los impuestos a la circulación y exportación de metálico eran otro manantial despojado al gobierno federal. Se trataba de uno de los más prominentes entre los que recolectaba la Administración de Rentas del Estado, y que derivaba después hacia Jefatura de Hacienda y Tesorería General. Su reglamentación y dominio hicieron que el poder regional no sólo los administrara, sino que, a la vez, tuviese mayores márgenes de negociación con los comerciantes, únicos que remitían hacia el exterior -en grandes cantidades y de manera sistemática- este vital cargamento.

La importancia de este ingreso crece especialmente desde 1858, cuando el gobernador y comandante Vidaurri reguló expresamente lo atinente a la circulación y exportación de la plata amonedada, del oro acuñado y de la planta en pasta. El 20 de enero fueron establecidos tributos específicos, además de hacer de Monterrey el centro de las recaudaciones respectivas en una vasta área del extremo norte: la base era un decreto que el 19 de mayo de 1854 había sancionado el presidente Santa Anna, y que Vidaurri interpretó a su peculiar manera ${ }^{36}$. En Monterrey debían tributar no sólo los mercaderes de Nuevo León-Coahuila y Tamaulipas. También, los de Chihuahua, Durango, Zacatecas y San Luis Potosí, en caso de que quisieran mantener contactos con el mercado internacional por las muy liberales aduanas del Noreste.

El anexo III muestra el impacto que tuvieron estos impuestos en los ingresos globales de la Administración de Rentas entre enero de 1858 y agosto del año siguiente. En los diecinueve meses allí computados ocuparon casi el 72 por ciento del total, con oscilaciones bastante fuertes de mes a mes. Obsérvese la repercusión de la plata pasta - prohibida en otros puntos del país como elemento exportable-, que prácticamente llegó a representar la mitad del impuesto al metálico $(179,673$ pesos, frente a 187,935 de la plata anıonedada).

\section{ECONOMIA DE GUERRA Y FORMACION DE CAPITALES}

La actividad mercantil y la presencia de fuertes comerciantes siempre cercanos a la esfera del poder político y militar, es una constante del lapso estudiado. No es algo casual, sino un dato estructural de la realidad investigada.

\footnotetext{
${ }^{35}$ Los gastos ordinarios de guerra se incluyeron en los cómputos de la tesorería, mensualmente, hasta diciembre de 1856. Posteriormente no son mencionados. En un resumen de la oficina, practicado en 1859, vuelven a citarse globalmente, por lo que puede inferirse que la pagaduría del Ejército del Norte mantenía informada a la tesorería sobre sus gastos. Pero éstos ya no se detallan en los cortes de caja que fueron la base de nuestros cálculos en 1858 × 1859

36 Las disposiciones de Vidauri del 20 de enero están en AGENL, Boletín Oficial, 23 de enero de 1858. El decreto de Santa Anna en Periódico Oficial del Gobierno del Departamento de Nuevo León, 22 de junio de 1854 .
} 
Ya fuere en los abastecimientos de guerra, ya en la problemática de las aduanas, en el financiamiento de las necesidades generadas por una profunda crisis nacional, en el uso de las ventajas que se otorgaban a la circulación y exportación de metálico, ya en el auge abrupto que traería desde 1861 la guerra de Secesión norteamericana (cuando el algodón del Sur esclavista debió salir hacia Europa por el noreste de México), los comerciantes -la burguesía en configuración-siempre jugaron un rol preponderante.

No podía ser de otra forma. Por variadas razones (entre las que destaca el hecho y a señalado de que concentraban casi exclusivamente gran parte de numerario que giraba en el país), los grupos mercantiles ocupaban una posición estratégica en la sociedad del México decimonónico. Fenómeno, por otro lado, repetible en casi toda América Latina en este siglo de transición.

La caótica situación que abrumaba a México no resultó obstáculo para la conformación de enormes fortunas en Monterrey y sus áreas aledañas. Por el contrario, los documentos consultados indican una y otra vez que de tan aguda y dramática coyuntura surgieron familias prósperas, y otras incrementaron ampliamente sus caudales. Los años en que Santiago Vidaurri reordenó el Noreste y lo adaptó a las nuevas circunstancias gestadas por el cambio de la línea fronteriza deben insertarse -en términos conceptuales - en el período de formación acelerada de capitales que en Monterrey precedió al surgimiento de la producción capitalista. Como ya hemos comentado, es desde 1890 -con el nacimiento de la industria fabril y la instalación de centenares de compañías mineras- cuando realmente se imponen en la ciudad y en el ámbito geográfico que la rodea los mecanismos capitalistas de producción.

Si intentáramos una cronología rigurosa, la etapa en que Vidaurri mantuvo su hegemonía en este sector de la frontera tendría que ser ubicada entre las más antiguas de este proceso de formación de capitales. Si bien algunos de los prósperos comerciantes de entonces no permanecen luego en Monterrey, otros, de similar envergadura, continuarán actuando y fortaleciéndose hasta el momento que - ya a fines de siglo- se lanzan a inversiones de magnitud en el plano de la producción; es decir, aprovecharán -en esa nueva conyuntura que se abre desde los noventa-, las condiciones que brindan la estabilidad porfiriana. los requerimientos diferentes de la economía mundial y la articulación y expansión de un mercado nacional.

Santiago Vidaurri necesitó y encontró apoyo en esta burguesía incipiente. $Y$ aunque por momentos las relaciones se tornaban tensas, en general podría indicarse que supo interpretar y plasmar las expectativas de este núcleo de activos mercaderes que situados en la lejana frontera noreste, aspiraban a competir con los siempre fuertes mercaderes de Veracruz y del centro de México. Convertida en eje político y militar de un vasto ámbito regional, no resulta extraño que Monterrey fuese, al mismo tiempo, pivote principal del tráfico mercantil. 
Los hábiles comerciantes no desaprovechaban las oportunidades. Las utilizaban con eficacia, no sólo como intermediarios sino también como poseedores de dinero efectivo, como prestamistas, labor en la que repetidamente actuaban para extraer dividendos jugosos de las necesidades estatales. Este último mecanismo resultaba tan ávido que disgustaba al propio Vidaurri: sus acusaciones a los mercaderes no faltan en los documentos, y tampoco calificativos como el de agiotista. A través del crédito, de préstamos condicionados, el gran traficante no sólo lograba intereses elevadísimos, sino que se aseguraba aranceles bajos, costos menos onerosos para la circulación y exportación de moneda, concesiones de diversa índole. Era un mecanismo que se articulaba aceitadamente, y no podía dejar de estimular la prosperidad de los comerciantes asentados en Monterrey y en otros puntos de la región.

La guerra de Reforma intensificaría este tipo de usos. En la circular del 22 de enero se explica sin tapujos que se tenía que recurrir a los mercaderes, a los que se abonaría un premio del once por ciento sobre sus anticipos. Muy frecuentemente, este premio oscilaba entre el once y el veinticinco por ciento, aunque en circunstancias muy críticas se elevaba incluso hasta el cincuenta por ciento.

Una recopilación no exhaustiva de los préstamos y cargos que se concretaron a la Tesorería General del Estado entre enero de 1858 y septiembre de 1859 figura en el anexo IV. Puede verse allí la vinculación directa entre necesidades de guerra y préstamos, así como la oscilación de los intereses que se cobraban y la compensación que de estos servicios se hacía vía derechos de importación o de impuestos a la circulación y exportación de metálico. Varios de los comerciantes allí citados -Patricio Milmo, Mariano Hernández, Valentin Rivero - fueron cabezas de núcleos familiares que participaron desde 1890 en la instalación de la industria fabril en la ciudad, en el surgimiento de bancos y en la implementación de numerosas compañías mineras.

La considerable significación que en las finanzas de Nuevo León-Coahuila asumió esta recurrente tendencia a acudir a la embrionaria burguesía regional, quedó reflejada en el informe que el tesorero del gobierno provisional de José Silvestre Aramberri (quien relevó circunstancialmente a Vidaurri, a fines de septiembre de 1859) elevó en octubre de este año. Reseñaba que los préstamos habían resultado un factor básico en los ingresos del estado desde el ascenso de Vidaurri al poder. Según sus cálculos, representaban casi el cuarenta por ciento $(1.303 .575$ pesos, frente a los 3.0303 .066 que había contabilizado la oficina). Pero eso no era lo más grave: la cuestión era cuánto le "há costado al pais" esta suma. Según su entender, "por lo muy bajo há 
costado el duplo", por "la diferencia entre los distintos aranceles que se há usado...y las rebajas y premios consedidos distintas veces y ultimamente por la circular de 22 de Enero del año próximo pasado"37

Los difíciles años que corrieron entre Ayutla y la derrota de los ejércitos europeos - de enorme repercusión en la historia del México decimonónicofueron una ocasión propicia para el nacimiento de fortunas sobre cuyas bases emergían núcleos burgueses significativos en el noreste del país, gestación que se vinculó a una economía de guerra y a un sistema regional de poder que permitió, además, aprovechar desde Monterrey la próspera coyuntura derivada de la guerra de Secesión norteamericana (1861-1865). Estos capitales modificarían su forma de operar entre 1870 y 1890 , atendiendo a los cambios que se registraban en el estado nacional que se consolidaba. Y en la última década del siglo -en respuesta a los requerimientos de la economía internacional y a la articulación y expansión del mercado interior - las más acaudalad as familias de Monterrey se lanzarían a la producción capitalista: industrial fabril y minería estarían en el eje de este nuevo proceso.

${ }^{37} \mathrm{Ac}$ (ENL, Hacendarios, 1859.24 de octubre. 


\section{ANEXO 1}

NOTICIA DE LAS GUIAS PRESENTADAS EN LA ADMINISTRACION DE RENTAS DEL ESTADO Desde el 25 de agosto hasta fin de septiembre de 1857 (a)

\begin{tabular}{|c|c|c|c|c|c|}
\hline Procedencia & Remitentes & $\begin{array}{l}\text { No. de bultos } \\
\text { y contenido }\end{array}$ & Valores (b) & Destinos & Consignatarios \\
\hline Mier & José Moses & $616 /$ mercancias & 19,937 & Monterrey, S. Luis, México & J.P. Molony \\
\hline Mier & J.P. Molony & 2 /hule & 195 & Monterrey & Patricio Milmo \\
\hline Matamoros & F.J. Rodríguez. & $539 /$ abarrotes & 431 & Monterrey, Saltillo y Zacatecas & A. San Román \\
\hline Matamoros & ldem & $10 /$ loza & 151 & Montcriey & Antonio Vignau \\
\hline Matamoros & G. de la Garza & $125 /$ varios & 728 & Monterrey & Jacobo Schwave \\
\hline Matamoros & ldem & $99 /$ ropa & 736 & Monterrey, S. Luis y México & Jacobo Schwave \\
\hline Matamoros & Hilario Itinojosa & $2 /$ medicinas & 32 & Monterrey & M. Garza Garcias \\
\hline Matamoros & G, de la Garza & 1/órgano & 54 & Monterrey, Chiluulua y Durango & José Oliver \\
\hline Matamoros & Idem & $36 /$ géneros & 1,286 & Monterrey, San Luis y México & J. P. Molony \\
\hline Matamoros & ldem & $36 /$ géneros & 1,286 & Monterrey, San Luis y México & J. P. Molony \\
\hline Tampico & J. J. Prom y Cía. & $6 / 10 z a$ & 32 & Monterrey, Saltillo y Chihuahua & Matras González \\
\hline Tampico & D. de la Lastra & 1/cinta & 41 & Monterrey, Saltillo y Durango & Valentín Rivero \\
\hline Tampico & Sánchoz y Cía. & $8 /$ camas latón & 84 & Monterrey, Durango y Colima & Lorenzo Oliver \\
\hline Matamoros & G. de la Garza & $71 /$ géneros & 2,359 & San Luis y México & F. Manautou \\
\hline Matamoros & A. Garza Chapa & 32 fgéneros & 1,143 & Monterrey & J. Garza y Chapa \\
\hline Matamoros & A. Garza Chapa & 58/géneros & 1,768 & Monterrey & J. Garza y Chapa \\
\hline Tampico & Ruge y Cía. & $1 /$ creas & 29 & Monterrey, Zacatecas y Chih. & Mariano llemández \\
\hline Tampico & Clausen y Cía. & $\begin{array}{l}1 / \text { pecheras de } \\
\text { camisas }\end{array}$ & 31 & Zacatecas, Durango y Chih. & Mariano Hernández. \\
\hline Matamoros & Antonio Longoria & lo/géneros & 457 & Monterrey, S. Luis y México & Al remitente \\
\hline Matamoros & Idem & 6/géneros & 186 & Monterrey, San Juan y México & ldem \\
\hline Matamoros & Idem & 10/géneros & 457 & Monterrey, Guanajuato y México & fdem \\
\hline Matamoros & Idem & $16 /$ gêneros & 564 & Monterrey, San Juan y México & ldem \\
\hline Matamoros & Idem & 10/generos & 455 & Monterrey, Zacatecas y México & ldem \\
\hline Matamoros & ldem & 8/generos & 383 & Monterrey,San Juan y México & Idem \\
\hline Matamoros & Idem & 13/géneros & 334 & Monterrey, San Juan y México & Idem \\
\hline Matanoros & B. García & 26/géneros & 1,068 & Linares, San Juan y Mćxico & Antonio Percyri \\
\hline Matamoros & Idem & 19/géneros & 1,400 & S. Luis, Zacatecas y México & Larroche y Cia. \\
\hline Matamoros & F. J. Rodríguez & 10/varios & 575 & Monterrey, Saltillo y Parras & Jacobo Schwave \\
\hline Matamoros & P. Solis & 31/varios & 73 & Monterrey & Al remitente \\
\hline Camargo & Toribio García & $2 /$ ropa hecha & 133 & Monterrey y Saltillo & D. D. Wolf \\
\hline Matamioros & Antonio Erhard & $78 /$ varios & 362 & Monterrcy & Daniel Brainard y Cía, \\
\hline Matamoros & F.J. Rodrígucz & 50/champaña & 50 & Monterrey, Zacatecas y Chilı. & Antonio Vignau \\
\hline Matamoros & Vicente Lankenan & $86 /$ varios & 19 & Monterrey & Clausen y Cía. \\
\hline Matamoros & A.N. Erhard & $213 /$ flerro y otros & 123 & Monterrey & Brainard y Cía. \\
\hline Matamoros & C. de Marans & 64/camas de fierro & 42 & Monterrey & Eduardo Grim \\
\hline Matamoros & F.J. Rodriguez & $1040 /$ varios & 1,363 & Monterrey, Zacatecas y Chilh. & Patricio Milmo \\
\hline Matamoros & Jdem & $60 /$ varios & 188 & Monterrey, Saltillo y Parras & Danicl Brainard \\
\hline Matamoros & Ideni & 2/loza de pedernal & 36 & Monterrey, Parras y Durango & Antonio Vignau \\
\hline Matamoros & Idcm & $475 /$ varios & 441 & Monterrey, Zacatecas y Chih. & Antonio Vignau \\
\hline Matamoros & 1 & & & & \\
\hline Matamoros & talem & $\begin{array}{l}21 / \text { balanzas y } \\
\text { baúles }\end{array}$ & 40 & Monterrey, Zacatecas y Chih. & Antonio Vignau \\
\hline Tampico & $\begin{array}{l}\text { Lelong Camacho } \\
\text { y Cís. }\end{array}$ & $6 /$ cera & 106 & Monterrey, Durango y Clith. & Mariano de la Garza \\
\hline Tampico & Clausen y Cía. & $2 /$ pana & 32 & Zacatecas, Durango y Chih. & Mariano Hernández \\
\hline Tampico & Ruge y Cía. & 6/ropa & 187 & Monterrey, Zacatecas y Chih. & Mariano Hernández \\
\hline Tampico & R. de Abregu & 8/ropa & 400 & Monterrey, Saltillo y Chih. & Clausen y Cía. \\
\hline Mier & Santiago Grogan & $80 /$ palas de fierro & 37 & Monterrey & Patricio Milmo \\
\hline \multicolumn{6}{|c|}{$\begin{array}{l}\text { (a) Se trata de cargamentos procedentes de las aduamas citadas. El documento lia sido sintetizado, excluyendo datos menos } \\
\text { significativos. } \\
\text { (b) Las sumas han sido redonderdas, eliminando centavos. }\end{array}$} \\
\hline
\end{tabular}

FUENTE: AGENL, Minutas, 1857-58, 12 de octubre de 1857. 


\section{ANEXO II}

\section{LAS FINANZAS DE LA GUERRA EN 1858}

Enero a septiembre, según la Tesorería General del Estado

\begin{tabular}{|c|c|c|c|c|c|c|c|c|c|c|c|}
\hline & Ene & Feb & Mzo & Abr & May & Jun & Jul & Ago & Sep & sumas(a) & $\%(b)$ \\
\hline Ingresos totales & 43.867 & 70.598 & 74.188 & 54.952 & 63.495 & 52.740 & 155.632 & 77.828 & 68.523 & 661.823 & \\
\hline $\begin{array}{l}\text { Préstamos de } \\
\text { pronto reintegro }\end{array}$ & 10.681 & 15.990 & 5.233 & 24.240 & 39.443 & 17.605 & 83.870 & 13.151 & 25.022 & 235.235 & 35,54 \\
\hline $\begin{array}{l}\text { Remisiones aduanas } \\
\text { de Matamoros (c) }\end{array}$ & (........... & -...- & 34.422 & 5.741 & 863 & 10.855 & 21.220 & 12.428 & 1.490 & 91.016 & 13,75 \\
\hline Alcabalas & 5.690 & 5.112 & 6.188 & 7.014 & 2.518 & 12.610 & 20.577 & 33.853 & 32.753 & 126.315 & 19,08 \\
\hline \multicolumn{12}{|c|}{$-------------\cdots$} \\
\hline Egresos totales & 31.364 & 35.187 & 33.693 & 42.960 & 20.268 & 31.362 & 63.033 & 266.016 & 37.157 & 561.640 & \\
\hline $\begin{array}{l}\text { Préstamos de } \\
\text { pronto reintegro }\end{array}$ & 10.754 & 4.334 & 11.446 & 18.842 & 5.230 & 16.138 & 22.706 & 12.447 & 23.864 & 125.761 & 22,39 \\
\hline $\begin{array}{l}\text { Gastos extraordina- } \\
\text { rios de guerra }\end{array}$ & 14.297 & 26.909 & 11.526 & 6.141 & 10.640 & 6.485 & 27.733 & 95.505 & 7.884 & 207.120 & 36,87 \\
\hline
\end{tabular}

FUENTES: Archivo General del estado de Nuevo León (AGENL), Hacendarios, 1858, Tesorería General del estado de Nuevo León y Coahuila. 
ANEXO III

IMPUESTOS SOBRE EL METALICO EN 1858 - 1859 (a)

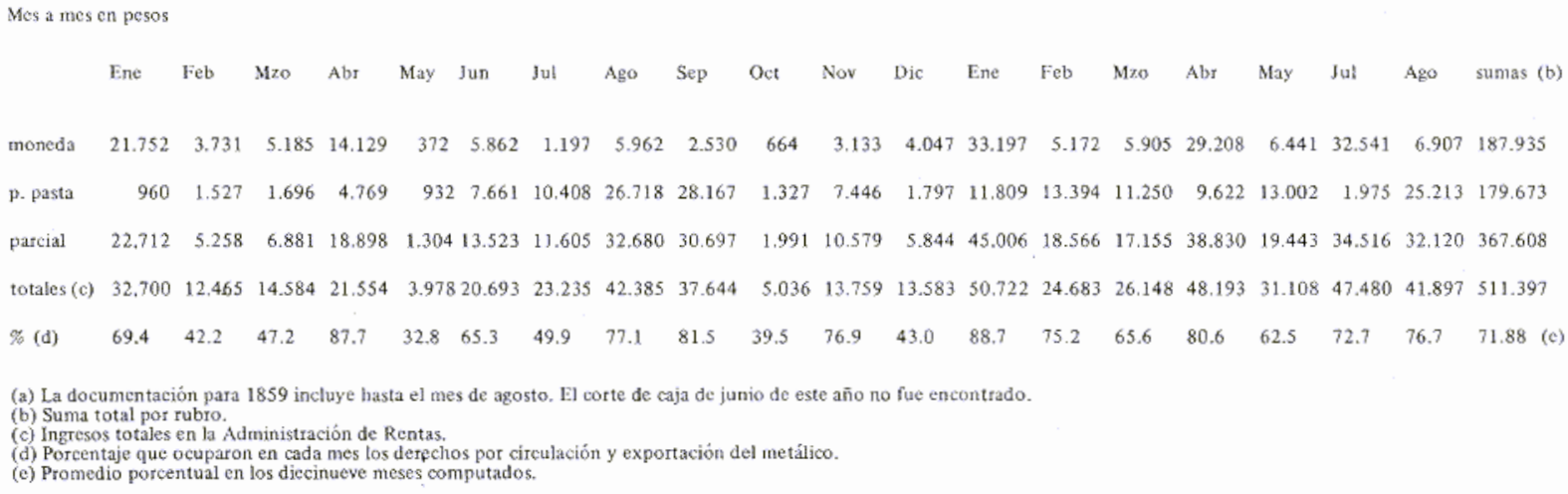

FUENTES: AGENL, Hacendarios, 1858 - 1859; cortes de caja de la Administración de Rentas. 
ANEXO IV

PRESTAMOS Y CARGOS A LA TESORERIA GENERAL DEL ESTADO (1858-1859)

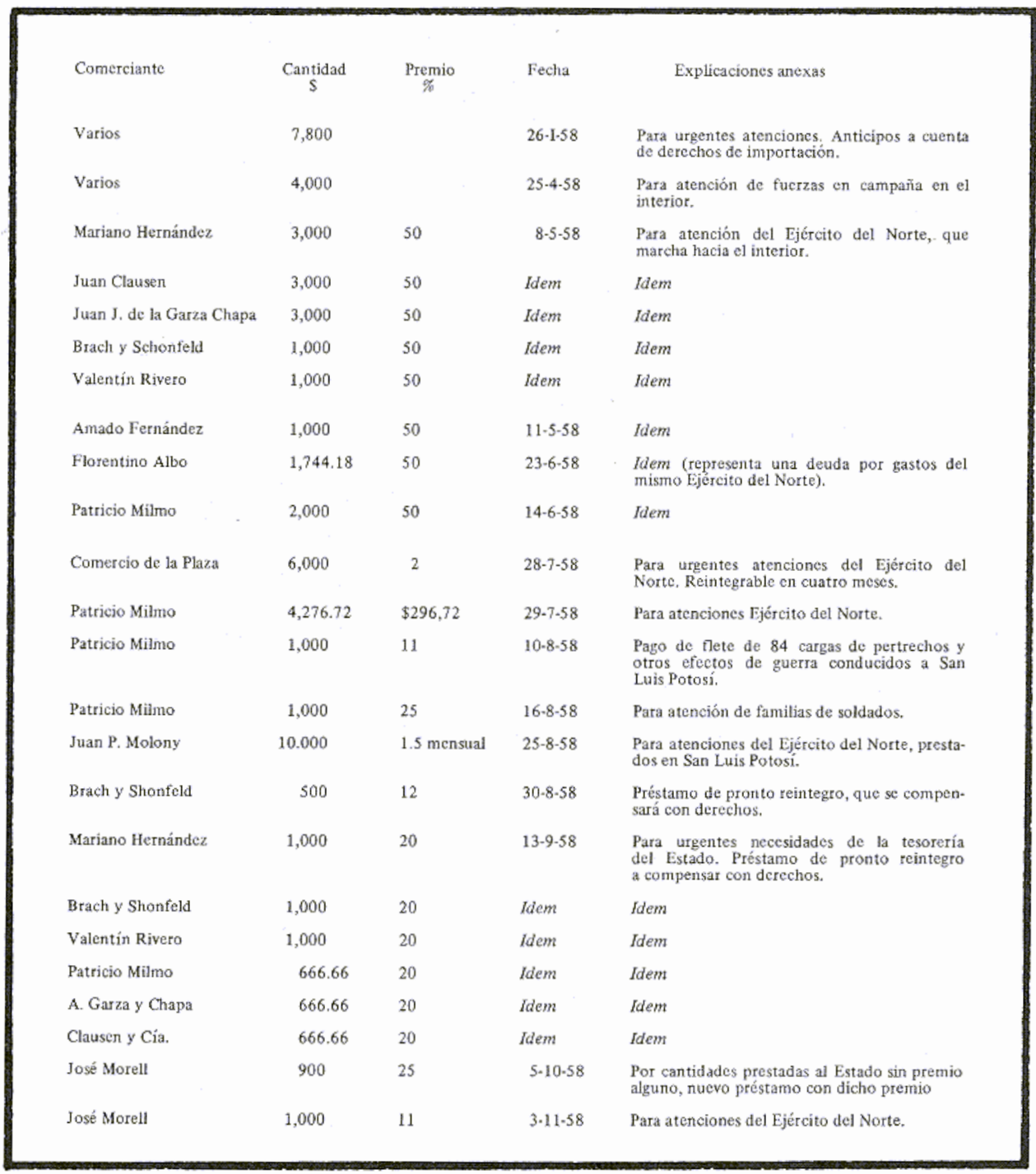




\begin{tabular}{|c|c|c|c|c|}
\hline Comerciante & $\underset{\$}{\text { Cantidad }}$ & $\underset{\%}{\text { Premio }}$ & Fecha & Explicaciones anexas \\
\hline Antonio de la Garza & 1,000 & 11 & $4-12-58$ & Para pago de armas \\
\hline Teófilo de la Garza & 1,000 & 11 & Idem & Idem \\
\hline Mariano Hernández & 400 & 11 & $12 \cdot 1 \cdot 59$ & Se devolverá con derechos \\
\hline Juan P. Molony & 2,265 & -- & $24 \cdot 1 \cdot 59$ & $\begin{array}{l}\text { Compensa intereses y otros, sobre la base del } \\
\text { préstamo efectuado en San Luis, de } 10,000 \\
\text { pesos, el } 25-1.58 \text {. }\end{array}$ \\
\hline Juan Clausen & 1,000 & 11 & $25 \cdot 2 \cdot 59$ & $\begin{array}{l}\text { A Pagaduría del ejército. Se retribuirá con } \\
\text { derechos. }\end{array}$ \\
\hline Viuda de Tárnava y Cía. & 1,000 & 11 & $2-3-59$ & $\begin{array}{l}\text { Para atenciones urgentes y como anticipo de } \\
\text { derechos. }\end{array}$ \\
\hline Idem & 2,000 & 11 & 14.3 .59 & $\begin{array}{l}\text { Como anticipo de derechos de circulación y } \\
\text { exportación de metálico. }\end{array}$ \\
\hline Mariano Hernández. & 1,269 & 11 & $21 \cdot 3.59$ & Para atenciones de servicio público. \\
\hline Brach y Shonfeld & 1,500 & 11 & $m z 0-59$ & $\begin{array}{l}\text { A pagar en la Administración de Rentas con } \\
\text { derechos. }\end{array}$ \\
\hline Juan Clausen & 500 & 11 & $8-4-59$ & \\
\hline Mariano Hernández & 1,500 & 11 & $a b r-59$ & Para atenciones militares. \\
\hline Valentín Rivero & 1,000 & 11 & 14.5 .59 & $\begin{array}{l}\text { Para atenciones del Ejército del Norte. Prés- } \\
\text { tamo de pronto reintegro. }\end{array}$ \\
\hline $\begin{array}{l}\text { Viuđa de Tárnava y Cía, } \\
\text { Juan Clausen - Brach y } \\
\text { Shonfeld - José Morell }\end{array}$ & 8,375 & 11 & $15 \cdot 5 \cdot 59$ & $\begin{array}{l}\text { Préstamo colectivo para atenciones del } \\
\text { Ejército del Norte. }\end{array}$ \\
\hline Juan Clausen & 400 & -.. & $17-5-59$ & $\begin{array}{l}\text { Para cubrir gastos del diputado Trinidad } \\
\text { de la Garza y Melo. A pagar con derechos } \\
\text { aduanales. }\end{array}$ \\
\hline Mariano Hernández & 500 & 11 & $24-5-59$ & Para atenciones del Ejército del Norte. \\
\hline $\begin{array}{l}\text { Mariano Hernández - Viuda } \\
\text { de Tárnava y Cía. - Juan } \\
\text { Clausen }\end{array}$ & 1,300 & 11 & $8-6.59$ & Para atenciones del Ejército del Norte. \\
\hline Patricio Milmo & 2,000 & 11 & $28-6 \cdot 59$ & Idem \\
\hline Juan P. Molony & 7,000 & 20 & $28 \cdot 7-59$ & Se carga a gastos extraordinarios de guerra. \\
\hline Mariano Hernández & 2,500 & 11 & $9-8-59$ & El premio se carga a extraordinarios de guerra. \\
\hline Viuda de Támava y Cía. & $2,445.75$ & 11 & 7.9 .59 & $\begin{array}{l}\text { Para atenciones del Ejército de! Norte. Se pa- } \\
\text { gará con derechos de exportación de moneda. }\end{array}$ \\
\hline Viuda de Tárnava y Cía. & 1,500 & 11 & $22-9-59$ & $\begin{array}{l}\text { A satisfacer con derechos de exportación de } \\
\text { metálico. }\end{array}$ \\
\hline Valentín Rivero & 300 & 11 & Idem & Idem \\
\hline Mariano Hernández & 1,500 & 11 & Idem & Idem \\
\hline Brach y Shonfeld & 600 & 11 & ldem & Idem \\
\hline
\end{tabular}

FUENTES: AGENL, Hacendarios, 1858 y 1859, Tesorería General del estado de Nuevo León y Coahuila. 